\title{
From dyad to triad: a survey on fathers' knowledge and attitudes toward breastfeeding
}

\author{
Beatrice Letizia Crippa ${ }^{1,2}$ - Alessandra Consales ${ }^{1,2}$ - Daniela Morniroli ${ }^{1,2}$ • Flavia Lunetto ${ }^{2}$. Maria Enrica Bettinelli ${ }^{2}$. \\ Patrizio Sannino $^{3}$ - Serena Rampini ${ }^{3}$ - Lidia Zanotta ${ }^{1}$ - Paola Marchisio ${ }^{4,5}$ - Laura Plevani ${ }^{1}$ - Maria Lorella Giannì ${ }^{1,2}$. \\ Fabio Mosca ${ }^{1,2} \cdot$ Lorenzo Colombo $^{1,2}$
}

Received: 22 October 2020 / Revised: 7 March 2021 / Accepted: 16 March 2021

(C) The Author(s) 2021

\begin{abstract}
Fathers are known to impact breastfeeding outcomes. We aimed to explore paternal knowledge and attitude toward breastfeeding, and possible association with breastfeeding rates at discharge. In this cross-sectional study, we enrolled 200 fathers of healthy term neonates. At discharge, fathers were asked to rate their degree of agreement to 12 items on a 5-point Likert scale. A total score was obtained from their answers. Univariate binary logistic regression analysis was used to verify if the total score was predictive of exclusive breastfeeding at discharge. A multivariable logistic regression model was then used to adjust for possible confounders. ROC analysis was performed, and a Youden's total score cutoff value was determined to define total score's performance in predicting exclusive breastfeeding at discharge. Fathers showed a solid knowledge of maternal (87\%) and neonatal (98\%) benefits of breastfeeding, skin-to-skin (99.5\%), rooming-in (79\%), and responsive feeding (67.5\%); conversely, only $51 \%$ knew about the recommended use of pacifiers. Fathers felt personally involved in babies' feeding in $79 \%$ of cases. An association was found between total score and exclusive breastfeeding at discharge at univariate (OR: 1.07, $p=0.04)$ but not at multivariable analysis (OR: 1.07, $p$ $=0.067$ ). ROC analysis was not statistically significant (AUC 0.58, $p=0.083$ ).

Conclusion: By using a novel instrument aimed at quantifying fathers' knowledge and overall attitude toward breastfeeding, this study underlines the importance of including fathers in the promotion of breastfeeding. Expanding the classic mother-baby dyad to a more modern mother-father-baby triad may impact breastfeeding outcomes at discharge.
\end{abstract}

Crippa Beatrice Letizia and Consales Alessandra contributed equally to this work.

Communicated by Daniele De Luca

Alessandra Consales

alessandra.consales@gmail.com

Beatrice Letizia Crippa

beatriceletizia.crippa@gmail.com

Daniela Morniroli

daniela.morniroli@gmail.com

Flavia Lunetto

flavia.lunetto@hotmail.it

Maria Enrica Bettinelli

maria.bettinelli@unimi.it

Patrizio Sannino

patrizio.sannino@policlinico.mi.it

Serena Rampini

serena.rampini@policlinico.mi.it

\author{
Lidia Zanotta \\ lidia.zanotta@mangiagalli.it \\ Paola Marchisio \\ paola.marchisio@unimi.it \\ Laura Plevani \\ laura.plevani@policlinico.mi.it \\ Maria Lorella Giannì \\ maria.gianni@unimi.it \\ Fabio Mosca \\ fabio.mosca@mangiagalli.it \\ Lorenzo Colombo \\ lorenzo.colombo@mangiagalli.it
}

Extended author information available on the last page of the article 
What is known:

- Social support plays a major role in improving breastfeeding outcomes.

- Fathers may greatly influence initiation and duration of breastfeeding; the more they know, the more helpful they can be.

What is new:

- A multidisciplinary team created a structured questionnaire aimed at quantifying fathers' knowledge and attitude toward breastfeeding.

- The association between a higher questionnaire total score and exclusive breastfeeding rates at discharge highlights the importance of including fathers in the promotion of breastfeeding, as part of the breastfeeding team.

Keywords Fathers $\cdot$ Paternal involvement $\cdot$ Knowledge $\cdot$ Attitude $\cdot$ Breastfeeding

\section{Background}

Breastfeeding is the cornerstone of newborns' nutrition. The World Health Organization (WHO) and the United Nations Children's Fund (UNICEF) recommend it as the exclusive mode of feeding of the infant for its first 6 months of life [1], given its well-known short- and long-term benefits for mother, child, and society [2-4]. The Baby-Friendly Hospital Initiative (BFHI) has been stressing healthcare professionals' role in the protection and promotion of breastfeeding since 1991 [5]. Nevertheless, outside of hospital facilities, social support plays an important role in determining breastfeeding outcomes [6]. Indeed, the Ten Steps to Successful Breastfeeding [7], which the BFHI relies upon, advise to facilitate families at discharge with timely access to ongoing support and care $\left(10^{\text {th }} \mathrm{Step}\right)$, thus ensuring continuity of care. Along this line, many countries, including Italy, have implemented the Baby-Friendly Community Initiative (BFCI), which is considered as an expansion and integration of the BFHI [8-10]. The global standards for the BFCI require the implementation of 7 Steps [9]. Among these steps, the third one advises to extend breastfeeding education to the whole family, and the sixth one encourages to provide a welcoming atmosphere for breastfeeding families.

At the same time, the evolution the role of fathers has undergone over the centuries, from a patriarchal breadwinning ideal to the modern involved co-parent [11], has facilitated the transition to a more family-centered approach of care.

A change of perspective has therefore been advocated to promote and facilitate the involvement of fathers in their newborns' health, thus expanding the center of attention from the classic mother-baby dyad to the more complex mother-fatherbaby triad [12].

Fathers' attitudes have a significant impact on mothers' breastfeeding decisions [13]. Fathers' psychological and practical support influences initiation and duration of breastfeeding [14], at the same time acting as a confidence booster for mothers, who develop a higher self-efficacy if they feel supported by their partners [15]. Supportive actions are heterogeneous in nature [16], but what drives them is the awareness of the importance of breastfeeding [17]. The more a father knows about breastfeeding benefits and management, the more likely he is to influence its initiation and continuation [13]. Moreover, according to a recent meta-analysis, targeting fathers in breastfeeding promotion in prenatal and postnatal settings improves exclusive breastfeeding rates at 4 and 6 months [18]. Therefore, it has been advocated that healthcare professionals favor a more meaningful engagement of fathers in their newborns' well-being, especially focusing on their key role of breastfeeding support [19].

However, little is known about what fathers in Italy know and how they feel about breastfeeding and its determinants and facilitators.

The present study aimed to investigate paternal knowledge and attitude toward breastfeeding, and their association with breastfeeding rates at discharge, in a cohort of fathers from an Italian neonatal tertiary referral center. Moreover, we created a novel instrument aimed at quantifying fathers' knowledge and overall attitude toward breastfeeding, and assessed its performance in predicting exclusive breastfeeding at discharge.

\section{Methods}

\section{Design and setting}

A cross-sectional study was conducted in May 2019 in the postnatal unit of our hospital, a tertiary referral center for neonatal care, which operates in compliance with the BFHI principles. Indeed, our hospital promotes and supports breastfeeding in all mother-infant dyads throughout hospital stay, following the principles of the BFHI. We have a written breastfeeding protocol, and we can rely on the presence of an International Board Certified Lactation Consultant (IBCLC) in situ. Nurses are actively involved in the promotion of breastfeeding and support at the bedside. At birth, skin-toskin practice is explained to all new parents and facilitated by pulse oximetry monitoring in case of skewed healthcare 
professional:dyad ratio. Likewise, rooming-in is encouraged and safety practices explained to both parents to ensure the well-being of the newborn. Our policies regarding rooming-in are described in greater detail elsewhere [20].

The institutional Ethics Committee approved the present study. Both mothers and fathers provided written informed consent for both the questionnaire and access to neonatal and maternal medical charts.

\section{Sample}

We enrolled a convenience sample of fathers of healthy term neonates born at our hospital after an uneventful single pregnancy in May 2019. We excluded (i) fathers without a good oral and written comprehension of the Italian language, (ii) fathers of neonates hospitalized in the Neonatal Intensive Care Unit (NICU) and/or affected by any condition that could interfere with breastfeeding, (iii) fathers of neonates small for gestational age $\left(<10^{\circ}\right.$ percentile), (iiii) fathers of twins, and (iv) fathers of neonates whose mothers had contraindications to breastfeeding (i.e., previous breast surgery, drugs incompatible with breastfeeding, HIV, or human T cell lymphotropic virus infection) and/or had chosen not to breastfeed.

Fathers of twins and neonates small for gestational age were excluded to obtain a homogeneous sample, considering the breastfeeding difficulties and lower breastfeeding rates reported in these newborns [21,22].

Partners of mothers with contraindications to breastfeeding were excluded based on the assumption that their attitude toward breastfeeding might be somewhat biased by the psychological impact of the impossibility to breastfeed.

\section{Data collection and procedures}

At discharge, a dedicated neonatologist proposed to fathers a self-administered structured questionnaire. The questionnaire took approximately $10 \mathrm{~min}$ to be filled out and was collected by the same healthcare professional $20 \mathrm{~min}$ after being handed out.

Obstetric charts and infants' computerized medical charts (Neocare, i\&t Informatica e Tecnologia Srl, Italy) were used to collect the basic characteristics of mothers and fathers (i.e., age, ethnicity, level of education, marital status, parity), current mode of feeding, and previous feeding experiences at discharge (none, exclusive breastfeeding, mixed feeding, bottle feeding).

For reporting purposes, maternal and paternal level of education was expressed in terms of years of education: $\leq 13$ (primary school, secondary school, and/or high school diplo$\mathrm{ma}$ ) and $>13$ years (university degree).

Mode of feeding was defined according to the WHO definitions [1].
All other data were obtained from the questionnaire.

\section{Instrument}

The structured self-administered questionnaire used for the purposes of the present study was created by a multidisciplinary team consisting of a neonatologist, an obstetrician, an IBCLC, and a pediatric nurse, inspired by the tool used by Brown et al. [23]. All the members of the multidisciplinary team work for our institution, a BFHI-compliant facility. The questionnaire was structured to follow the WHO/UNICEF Ten Steps for Successful Breastfeeding [7] and it was developed through a series of meetings during which each member of the multidisciplinary team was asked to express their agreement (or lack thereof) on the inclusion of the various items. Based on the percentage of team members agreeing with the inclusion of each item in the questionnaire, the items were included $(\geq 50 \%)$ or rejected $(<50 \%)$. The newly created questionnaire (Supplementary Table 1) was administered to a sample of 50 fathers ( 40 Italians and 10 foreigners) to ascertain items' comprehension; these 50 fathers were not considered part of the present study population, nor were they included in the statistical analysis. Fathers were asked to express any concern regarding the questionnaire in a specific section of the document provided. No specific issues emerged. No item of the questionnaire was subsequently changed.

The questionnaire showed acceptable internal consistency $($ Cronbach's alpha $=0.7)$.

The questionnaire encompassed 12 items divided into 9 sections (Supplementary Table 1). Fathers were required to rate their degree of agreement to each item on a 5-point Likert scale, ranging from "Strongly Disagree" (= 1 point) to "Strongly Agree" (= 5 points). A total score (min. 12, max. 60 points) for each father was obtained by adding up the points assigned to the various items. The first seven sections addressed 8 out of the 10 Steps for Successful Breastfeeding [7], as explained below: Section 1: antenatal care ( $3^{\text {rd }}$ Step), Section 2: perinatal care $\left(4^{\text {th }}\right.$ Step), Section 3: breastfeeding support ( $5^{\text {th }}$ Step), Section 4: rooming-in $\left(7^{\text {th }}\right.$ Step), Section 5: responsive feeding $\left(8^{\text {th }}\right.$ Step), Section 6 : use of pacifier $\left(9^{\text {th }}\right.$ Step), Section 7: staff competency, and information received at discharge ( $2^{\text {nd }}$ and $10^{\text {th }}$ Steps). Sections 8 and 9 investigated fathers' opinions on breastfeeding impact on everyday life and breastfeeding in public.

In order not to compromise the authenticity of the responses, fathers were asked to fill out the questionnaire independently, without sharing their answers with their partner.

\section{Statistical analyses}

Categorical variables were expressed as frequencies. Continuous variables were expressed as mean \pm standard deviation $(\mathrm{SD})$ or median [inter-quartile range]. Non-parametric 
tests were used to assess differences in total scores between subgroups. The variables considered were basic characteristics of fathers (age, ethnicity, level of education) and breastfeeding experience (maternal parity and previous feeding experiences at discharge). The total score was obtained by adding up the points assigned to each item in the questionnaire (min 12, max 60 points): a higher score was considered as indicative of greater knowledge and positive attitude toward breastfeeding.

Univariate binary logistic regression analysis was used to verify if the total score was a predictor of exclusive breastfeeding at discharge. Likewise, univariate analysis was used for variables reported in the literature to be predictive of exclusive breastfeeding [24, 25]. Variables found to be significant at univariate analysis were entered into a multivariable logistic regression model to adjust for possible confounders. ROC analysis (Fig. 1) was then performed, and a Youden's total score cut-off value was determined to define the total score's performance in predicting exclusive breastfeeding at discharge.

Statistical analyses were performed using SPSS version 25 Statistic Software Package (SPSS Inc., Chicago, IL, USA).

For reporting purposes, data from the questionnaire are shown categorized into three groups: agree (Likert scale 4 and 5), disagree (Likert scale 1 and 2), and neutral (Likert scale 3).

\section{Results}

The total eligible population consisted of 210 fathers. Seven of them $(3.3 \%)$ were not included in the study based on the

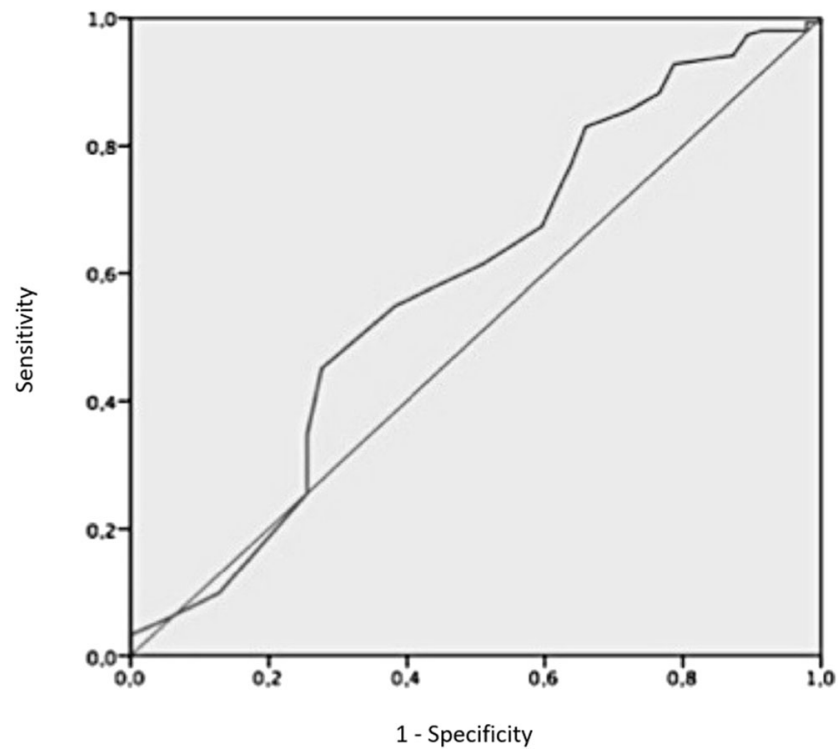

Fig. 1 Receiver operating characteristic (ROC) curve for total score values obtained from all participants. AUC $0.58, p=0.083,95 \%$ CI $0.485-0.683$ exclusion criteria, and $3(1.4 \%)$ refused to participate. The enrolled population included 200 fathers who completed the questionnaire. Basic characteristics of the mother-father couples enrolled are summarized in Table 1.

The mean paternal and maternal age were $37.2 \pm 5$ and 34.6 \pm 5 years, respectively. The sample comprised mainly Italian parents with a high level of education ( $>13$ years). More than half of the participants were married (60\%).

Most mothers were primiparous $(68 \%)$ and had a spontaneous delivery (56\%). Only 36 mothers (18\%) had previous experience of exclusive breastfeeding at discharge, while 139 $(69.5 \%)$ had no experience at all. Exclusive breastfeeding rate at discharge was $76.5 \%$.

The answers to the items assessed in the questionnaire are shown in Table 2. No missed data were reported. Most fathers were aware of breastfeeding benefits for infants (98\%),

Table 1 Basic characteristics of study population

\begin{tabular}{|c|c|c|}
\hline \multicolumn{3}{|c|}{ Sociodemographic features } \\
\hline & Fathers $(n=200)$ & Mothers $(n=200)$ \\
\hline Age, years $($ mean $\pm \mathrm{SD})$ & $37.2 \pm 5$ & $34.6 \pm 5$ \\
\hline \multicolumn{3}{|l|}{ Ethnicity, $N(\%)$} \\
\hline Italian & $191(95.5)$ & $175(87.5)$ \\
\hline European & $3(1.5)$ & $15(7.5)$ \\
\hline Other & $6(3)$ & $10(5)$ \\
\hline \multicolumn{3}{|l|}{ Level of education, $N(\%)$} \\
\hline$\leq 13$ years & $86(43)$ & $67(33.5)$ \\
\hline$>13$ years & $114(57)$ & $133(66.5)$ \\
\hline \multicolumn{3}{|l|}{ Marital status, $N(\%)$} \\
\hline Married & $120(60)$ & \\
\hline Unmarried relationship & $80(40)$ & \\
\hline \multicolumn{3}{|c|}{ Delivery and breastfeeding experience } \\
\hline & Mothers $(n=200)$ & \\
\hline \multicolumn{3}{|l|}{ Parity, $N(\%)$} \\
\hline Primiparous & $136(68)$ & \\
\hline Multiparous & $64(32)$ & \\
\hline \multicolumn{3}{|l|}{ Type of delivery, $N(\%)$} \\
\hline Spontaneous & $112(56)$ & \\
\hline Cesarean section & $88(44)$ & \\
\hline \multicolumn{3}{|c|}{ Previous feeding experience at discharge, $N(\%)$} \\
\hline None & $139(69.5)$ & \\
\hline Exclusive breastfeeding & $36(18)$ & \\
\hline Mixed feeding & $15(7.5)$ & \\
\hline Bottle feeding & $10(5)$ & \\
\hline \multicolumn{3}{|c|}{ Feeding at discharge, $N(\%)$} \\
\hline Exclusive breastfeeding & $153(76.5)$ & \\
\hline Mixed feeding & $35(17.5)$ & \\
\hline Bottle feeding & $12(6)$ & \\
\hline
\end{tabular}

This table presents the basic characteristics of the mother-father couples who participated in the study 
Table 2 Answers to the selfadministered questionnaire

\begin{tabular}{|c|c|c|c|c|}
\hline \multicolumn{2}{|c|}{ Questions } & \multicolumn{3}{|c|}{ Fathers $(n=200)$} \\
\hline & & $\begin{array}{l}\text { Agree } \\
N(\%)\end{array}$ & $\begin{array}{l}\text { Disagree } \\
N(\%)\end{array}$ & $\begin{array}{l}\text { Neutral } \\
N(\%)\end{array}$ \\
\hline \multirow[t]{5}{*}{1} & Antenatal care (3rd step) & & & \\
\hline & I received sufficient information on breastfeeding management & $135(67.5)$ & $65(32.5)$ & - \\
\hline & Breastfeeding offers health benefits for infants & $196(98)$ & $2(1)$ & $2(1)$ \\
\hline & Breastfeeding offers health benefits for mothers & $174(87)$ & $24(12)$ & $2(1)$ \\
\hline & Breastfeeding benefits society & $129(64.5)$ & $59(29.5)$ & $12(6)$ \\
\hline \multirow[t]{2}{*}{2} & Perinatal care (4th step) & & & \\
\hline & Skin-to-skin contact after birth is a valuable opportunity & $199(99.5)$ & $1(0.5)$ & - \\
\hline \multirow[t]{2}{*}{3} & Breastfeeding support (5th step) & & & \\
\hline & I feel personally involved in feeding my baby & $158(79)$ & $42(21)$ & - \\
\hline \multirow[t]{2}{*}{4} & Rooming-in (7th step) & & & \\
\hline & Rooming-in affects breastfeeding initiation & $158(79)$ & $30(15)$ & $12(6)$ \\
\hline \multirow[t]{2}{*}{5} & Responsive feeding (8th step) & & & \\
\hline & Breastfeeding on-demand is beneficial & $135(67.5)$ & $54(27)$ & $11(5.5)$ \\
\hline \multirow[t]{2}{*}{6} & Use of pacifier (9th step) & & & \\
\hline & $\begin{array}{l}\text { Breastfed infants should not use pacifiers in the first month } \\
\text { of life }\end{array}$ & $102(51)$ & $79(39.5)$ & $19(9.5)$ \\
\hline \multirow[t]{2}{*}{7} & Staff competency and discharge (2nd and 10th step) & & & \\
\hline & $\begin{array}{l}\text { Information received during hospital stay and at discharge } \\
\text { was clear }\end{array}$ & $174(87)$ & $18(9)$ & $8(4)$ \\
\hline 8 & Breastfeeding does not complicate everyday life & $59(29.5)$ & $129(64.5)$ & $12(6)$ \\
\hline 9 & Mothers can breastfeed wherever they are & $186(93)$ & $14(7)$ & - \\
\hline
\end{tabular}

This table provides details of the answers to the various items of the questionnaire given by fathers enrolled in the study mothers $(87 \%)$, and society $(64.5 \%)$, and $135(67.5 \%)$ stated that they had received sufficient information on breastfeeding management during pregnancy. Almost all fathers believed in the importance of skin-to-skin contact after birth $(99.5 \%)$ and rooming-in (79\%). Most of them (79\%) felt directly involved in breastfeeding their baby regardless of type of feeding (exclusive vs. non-exclusive breastfeeding, $p=0.752$ ) and considered breastfeeding on demand beneficial (67.5\%). Only $51 \%$ of fathers were aware of the recommended restrictions on pacifier use in the first month of life. Information received during hospital stay was considered clear by $87 \%$ of fathers. One-hundred and twenty-nine fathers $(64.5 \%)$ thought that breastfeeding could lead to difficulties in everyday life, and $186(93 \%)$ were supportive of breastfeeding in public.

No difference in total score median values was found between the subgroups analyzed, based on the following variables: paternal age, level of education, ethnicity, maternal parity, and previous feeding experience at discharge (Supplementary Table 2).

The total score was found to be associated with exclusive breastfeeding at discharge at univariate analysis (OR: 1.07, $p$
$=0.04 ; 95 \%$ CI $1.002-1.152)$. In a multivariable model including maternal age, parity, mode of delivery, and total score, parity and mode of delivery were found to be independently associated with exclusive breastfeeding at discharge (OR: 4.42 and $3.07, p=0.0001$ and 0.004 , respectively), while total score was not (OR: 1.07, $p=0.067)$. When a total score of 50 was chosen as a cut-off value, it resulted in a sensitivity of $54.9 \%$ and a specificity of $61.7 \%$ in predicting exclusive breastfeeding at discharge. However, ROC analysis performed to assess the predictive power of the total score was not statistically significant (AUC $0.58, p=0.083,95 \%$ CI 0.485-0.683).

\section{Discussion}

In the present study, fathers enrolled were reasonably well informed about breastfeeding. Almost all fathers were aware of the beneficial effects of breastfeeding on infants' and mothers' health, skin-to-skin contact, rooming-in practice, and responsive feeding. However, only half of them were 
aware of the recommendations on the use of pacifiers for breastfed infants. Moreover, fathers showed an overall positive attitude toward breastfeeding, although pointing out that breastfeeding does complicate everyday life, and generally felt personally involved in their babies' feeding, regardless of type of feeding. An association was found between the total score of the questionnaire proposed to fathers and exclusive breastfeeding at discharge at univariate, although not at multivariable analysis.

It has been described how fathers play an important role in the initiation and duration of breastfeeding. According to BarYam and Darby [26], fathers may influence four different aspects: the breastfeeding decision, assistance at first feeding, duration of breastfeeding, and risk factors for artificial feeding. Two systematic reviews $[18,27]$ reported how an increased paternal breastfeeding knowledge can positively affect breastfeeding outcomes (initiation, exclusivity, and continuation). Two randomized controlled trials showed how educating fathers for the role of "breastfeeding coach" has positive effects on breastfeeding in terms of increased initiation rate, reduced worry about low milk supply, and reduced premature breastfeeding cessation $[13,28]$. Moreover, in a recent review, Sihota et al. highlighted the need for comprehensive antenatal support and education tailored for fathers of breastfed infants [29]. Interestingly, some authors have reported how fathers themselves want to know more about breastfeeding $[13,29]$. Most fathers enrolled stated that they had received sufficient information either before their baby's birth or during hospital stay or at discharge. The high percentage of answers in line with the BFHI principles demonstrates a generally solid knowledge of the subject.

A recent study by Chen et al. reported lower Quality of Life scores in fathers of breastfed infants than in fathers of bottlefed infants, mainly due to the perceived more limited bonding opportunities with the baby [30]. Paternal postpartum depression is a worrying reality, connected with feelings of inadequacy and reduced self-efficacy often prompted by a sense of uselessness when compared to the mother's nursing role [31]. Greater paternal involvement in breastfeeding may provide fathers with more occasions to bond with their newborn, thus proving beneficial for their mental health as well [31]. The fact that fathers in our study felt generally involved in their babies' feeding, regardless of type of feeding, should therefore be regarded as a positive, well-boding result.

A high percentage of fathers interviewed declared to be in favor of breastfeeding in public, a possible sign of the changing times. Breastfeeding in public is still a controversial issue [32]: several studies have reported how it is often perceived by men as uncomfortable, embarrassing, and even distasteful [23, 33-35], showing a correlation with socio-economic status [34, $35]$ and cultural background $[29,36]$. A significant push toward the rethinking of breastfeeding in public has been given by the implementation of the BFCI [9]. In particular, the $6^{\text {th }}$
Step of the BFCI [9] aims at the creation of breastfeedingfriendly environments, where nursing mothers can feel welcome. As Boyer pointed out in a recent paper, acceptance of breastfeeding in public is, first of all, a cultural issue that the government could help address by implementing programs that challenge current social norms [37].

Finally, at univariate analysis, an association was found between the total score obtained from the questionnaire and exclusive breastfeeding at discharge. Exclusive breastfeeding rate at discharge (76.5\%) was comparable to what was previously reported in our population (75\%) [38]; it resulted higher than the national $(57.2 \%)$ and regional average $(67.3 \%)$ [39, 40], and in line with the WHO/UNICEF Global Strategy for Infant and Young Child Feeding recommended rate of 75\% [41]. The higher the score is (hence paternal knowledge of and positive attitude toward breastfeeding), the higher the probability of exclusive breastfeeding at discharge is. The association between a higher questionnaire total score and exclusive breastfeeding rates at discharge may indicate a potential positive influence of fathers on newborn's feeding choices at discharge. However, multivariable analysis did not confirm the association between total score and exclusive breastfeeding at discharge when adjusting for possible confounders. The limited number of fathers included in the study, together with the strong effect of parity and mode of delivery on exclusive breastfeeding rates at discharge, may be responsible for this result. The statistical power of our questionnaire in predicting exclusive breastfeeding at discharge was understandably limited, since it seems unrealistic to expect of any test to reliably predict such a complex outcome, bound for its very nature to be influenced by numerous factors. However, our results are in line with the current international literature [42] in highlighting how fathers more invested in breastfeeding and more informed about how it may influence their newborns' feeding choices.

Therefore, there appears to be an ever-growing need for father-focused interventions to teach fathers how to better help and support their partners, thus expanding the classic motherbaby dyad to include them as well, as part of the breastfeeding team $[29,43]$.

We acknowledge that the present study has some limitations. Firstly, data were collected from a single Italian center; thus, our results and subsequent considerations may not apply to different settings. Specifically, the unique demographic of fathers participating in this study does not allow comparisons with other studies addressing the same topic in different populations. Furthermore, our study population consists of fathers who purposefully chose with their partner to deliver their baby in a BFHI-compliant hospital. This may have potentially determined a selection bias of fathers more sensitive and open to breastfeeding. Secondly, breastfeeding rates were evaluated only at discharge. A long-term follow-up would probably add more interesting information. Moreover, we acknowledge 
that all items of the questionnaire used are worded in the direction that favors breastfeeding, and, as such, may have led the subjects, resulting in higher scores than an instrument including questions worded more neutrally. Finally, it would have been interesting to compare knowledge and attitude toward breastfeeding between fathers whose partners aimed to breastfeed and fathers whose partners did not. Likewise, it would have been interesting to evaluate mothers' knowledge and attitude toward breastfeeding together with their partners to understand if there is any interaction between the two. These topics could be addressed in future research.

However, our study provides valuable insight into the personal breastfeeding experience of fathers of newborns born at our center, since it addressed a relatively large number of fathers, whose answers were blinded to mothers, thus not influenced by their partners' opinions.

\section{Conclusions}

Socio-cultural changes are progressively pushing toward a greater involvement of fathers in what was once thought as a "women's job" only. Within the multifaceted network of social support (family, friends, healthcare professionals) that revolves around mothers, fathers are especially influential in improving breastfeeding outcomes [42]. Providing fathers with more breastfeeding information both pre- and postnatally and prompting a favorable attitude toward it could improve long-term exclusive breastfeeding rates, although further studies, maybe multicentric and with a long followup period, are needed to confirm this hypothesis.

Abbreviations BFCI, Baby-Friendly Community Initiative; BFHI, Baby-Friendly Hospital Initiative; IBCLC, International Board Certified Lactation Consultant; NICU, Neonatal Intensive Care Unit; UNICEF, United Nations Children's Fund; WHO, World Health Organization

Supplementary Information The online version contains supplementary material available at https://doi.org/10.1007/s00431-021-04034-x.

Acknowledgements The authors would like to thank the parents who participated in the present study.

Authors' contributions BLC and AC contributed to the design of the study, carried out the statistical analysis, and drafted the initial manuscript. DM contributed to the interpretation of results and reviewed and revised the manuscript. FL collected the data and contributed to the interpretation of results. MEB contributed to the interpretation of results and reviewed and revised the manuscript. PS, SR, LZ, PM, and LP contributed to the design of the study, supervised the data collection, and reviewed the manuscript. MLG contributed to the design of the study, supervised the data collection, contributed to the interpretation of results, and reviewed and revised the manuscript. FM contributed to the design of the study and reviewed and revised the manuscript. LC contributed to the design of the study, supervised the data collection, contributed to the interpretation of results, and reviewed and revised the manuscript. All authors gave final approval of the manuscript version submitted for publication.

Funding Open access funding provided by Università degli Studi di Milano within the CRUI-CARE Agreement.

Data Availability Access to the dataset generated and analyzed during the current study is restricted to protect patient confidentiality and participant privacy. The dataset is available from the corresponding author upon reasonable request.

Code availability Not applicable.

\section{Declarations}

Ethics approval and consent to participate The study was reviewed and approved by the Ethics Committee of Fondazione IRCCS Ca' Granda Ospedale Maggiore Policlinico, Milan, Italy. Written informed consent to participate in this study was provided by all participants.

Consent for publication Not applicable.

Competing interests The authors declare no competing interests.

Open Access This article is licensed under a Creative Commons Attribution 4.0 International License, which permits use, sharing, adaptation, distribution and reproduction in any medium or format, as long as you give appropriate credit to the original author(s) and the source, provide a link to the Creative Commons licence, and indicate if changes were made. The images or other third party material in this article are included in the article's Creative Commons licence, unless indicated otherwise in a credit line to the material. If material is not included in the article's Creative Commons licence and your intended use is not permitted by statutory regulation or exceeds the permitted use, you will need to obtain permission directly from the copyright holder. To view a copy of this licence, visit http://creativecommons.org/licenses/by/4.0/.

\section{References}

1. WHO | Exclusive breastfeeding for optimal growth, development and health of infants. In: WHO. http://www.who.int/elena/titles/ exclusive breastfeeding/en/. Accessed 25 May 2019

2. Chowdhury R, Sinha B, Sankar MJ et al (2015) Breastfeeding and maternal health outcomes: a systematic review and meta-analysis. Acta Paediatr 104:96-113. https://doi.org/10.1111/apa.13102

3. Ip S, Chung M, Raman G et al (2007) Breastfeeding and maternal and infant health outcomes in developed countries. Evid Rep Technol Assess (Full Rep):1-186

4. Victora CG, Bahl R, Barros AJD et al (2016) Breastfeeding in the 21st century: epidemiology, mechanisms, and lifelong effect. Lancet 387:475-490. https://doi.org/10.1016/S0140-6736(15) 01024-7

5. WHO | Baby-friendly Hospital Initiative. In: WHO. http://www. who.int/nutrition/topics/bfhi/en/. Accessed 6 Jan 2020

6. Meedya S, Fahy K, Kable A (2010) Factors that positively influence breastfeeding duration to 6 months: a literature review. Women Birth 23:135-145. https://doi.org/10.1016/j.wombi.2010. 02.002

7. WHO | Ten steps to successful breastfeeding (revised 2018). In: WHO. http://www.who.int/nutrition/bfhi/ten-steps/en/. Accessed 25 May 2019 
8. Radford A, Rickitt C, Williams A (1998) Breast feeding: the baby friendly initiative. BMJ 317:1385

9. Bettinelli ME, Chapin EM, Cattaneo A (2012) Establishing the Baby-Friendly Community Initiative in Italy: development, strategy, and implementation. J Hum Lact 28:297-303. https://doi.org/ 10.1177/0890334412447994

10. Kavle JA, Ahoya B, Kiige L et al (2019) Baby-Friendly Community Initiative - from national guidelines to implementation: a multisectoral platform for improving infant and young child feeding practices and integrated health services. Matern Child Nutr 15(Suppl 1):e12747. https://doi.org/10.1111/mcn.12747

11. Pleck E, Pleck J (1997) Fatherhood ideals in the United States: historical dimensions. The father's role in child development

12. Ribeiro AFC (2005) At last dyad becomes triad? An evolution of the concept of father and his participation during birth of child. Servir 53:190-194

13. Wolfberg AJ, Michels KB, Shields W et al (2004) Dads as breastfeeding advocates: results from a randomized controlled trial of an educational intervention. Am J Obstet Gynecol 191:708-712. https://doi.org/10.1016/j.ajog.2004.05.019

14. Swanson V, Power KG (2005) Initiation and continuation of breastfeeding: theory of planned behaviour. J Adv Nurs 50:272282. https://doi.org/10.1111/j.1365-2648.2005.03390.x

15. Mannion CA, Hobbs AJ, McDonald SW, Tough SC (2013) Maternal perceptions of partner support during breastfeeding. Int Breastfeed J 8:4. https://doi.org/10.1186/1746-4358-8-4

16. Tohotoa J, Maycock B, Hauck YL et al (2009) Dads make a difference: an exploratory study of paternal support for breastfeeding in Perth, Western Australia. Int Breastfeed J 4:15. https://doi.org/10. 1186/1746-4358-4-15

17. Ngoenthong P, Sansiriphun N, Fongkaew W, Chaloumsuk N (2019) Integrative review of fathers' perspectives on breastfeeding support. J Obstet Gynecol Neonatal Nurs. https://doi.org/10.1016/j. jogn.2019.09.005

18. Mahesh PKB, Gunathunga MW, Arnold SM et al (2018) Effectiveness of targeting fathers for breastfeeding promotion: systematic review and meta-analysis. BMC Public Health 18:1140. https://doi.org/10.1186/s12889-018-6037-x

19. Sherriff N, Hall V, Panton C (2014) Engaging and supporting fathers to promote breast feeding: a concept analysis. Midwifery 30: 667-677. https://doi.org/10.1016/j.midw.2013.07.014

20. Consales A, Crippa BL, Cerasani J et al (2020) Overcoming rooming-in barriers: a survey on mothers' perspectives. Front Pediatr 8:53. https://doi.org/10.3389/fped.2020.00053

21. Whitford HM, Wallis SK, Dowswell T et al (2017) Breastfeeding education and support for women with twins or higher order multiples. Cochrane Database Syst Rev. https://doi.org/10.1002/ 14651858.CD012003.pub2

22. Dooks E, Owens D, Stacey T (2020) The establishment of breastfeeding in the small-for-gestational-age baby. Br J Midwifery 28:90-95. https://doi.org/10.12968/bjom.2020.28.2.90

23. Brown A, Davies R (2014) Fathers' experiences of supporting breastfeeding: challenges for breastfeeding promotion and education. Matern Child Nutr 10:510-526. https://doi.org/10.1111/men. 12129

24. Hernández-Cordero S, Lozada-Tequeanes AL, Fernández-Gaxiola $\mathrm{AC}$ et al (2020) Barriers and facilitators to breastfeeding during the immediate and one month postpartum periods, among Mexican women: a mixed methods approach. Int Breastfeed J 15:87. https://doi.org/10.1186/s13006-020-00327-3

25. Agea-Cano I, Linares-Abad M, Ceballos-Fuentes AG, CaleroGarcía MJ (2020) Breastfeeding at 1, 3 and 6 months after birth according to the mode of birth: a correlation study. IJERPH 17: 6828. https://doi.org/10.3390/ijerph17186828

26. Bar-Yam NB, Darby L (1997) Fathers and breastfeeding: a review of the literature. J Hum Lact 13:45-50. https://doi.org/10.1177/ 089033449701300116

27. Mitchell-Box KM, Braun KL (2013) Impact of male-partnerfocused interventions on breastfeeding initiation, exclusivity, and continuation. J Hum Lact 29:473-479. https://doi.org/10.1177/ 0890334413491833

28. Pisacane A, Continisio GI, Aldinucci M et al (2005) A controlled trial of the father's role in breastfeeding promotion. Pediatrics 116: e494-e498. https://doi.org/10.1542/peds.2005-0479

29. Sihota H, Oliffe J, Kelly MT, McCuaig F (2019) Fathers' experiences and perspectives of breastfeeding: a scoping review. Am J Mens Health 13:1557988319851616. https://doi.org/10.1177/ 1557988319851616

30. Chen YC, Chie W-C, Chang P-J et al (2010) Is infant feeding pattern associated with father's quality of life? Am J Mens Health 4:315-322. https://doi.org/10.1177/1557988309350491

31. Kim P, Swain JE (2007) Sad dads: paternal postpartum depression. Psychiatry (Edgmont) 4:35-47

32. Sheehan A, Gribble K, Schmied V (2019) It's okay to breastfeed in public but.... Int Breastfeed J 14:24. https://doi.org/10.1186/ s13006-019-0216-y

33. Mitchell-Box K, Braun KL (2012) Fathers' thoughts on breastfeeding and implications for a theory-based intervention. $\mathrm{J}$ Obstet Gynecol Neonatal Nurs 41:E41-E50. https://doi.org/10. 1111/j.1552-6909.2012.01399.x

34. Henderson L, McMillan B, Green JM, Renfrew MJ (2011) Men and infant feeding: perceptions of embarrassment, sexuality, and social conduct in white low-income British men. Birth 38:61-70. https://doi.org/10.1111/j.1523-536X.2010.00442.x

35. Hansen E, Tesch L, Ayton J (2018) “They're born to get breastfed"-how fathers view breastfeeding: a mixed method study. BMC Pregnancy Childbirth 18:238. https://doi.org/10. 1186/s12884-018-1827-9

36. Abu-Abbas MW, Kassab MI, Shelash KI (2016) Fathers and breastfeeding process: determining their role and attitudes. Eur Sci J 12:327

37. Boyer K (2012) Affect, corporeality and the limits of belonging: breastfeeding in public in the contemporary UK. Health Place 18: 552-560. https://doi.org/10.1016/j.healthplace.2012.01.010

38. Colombo L, Crippa BL, Consonni D, et al (2018) Breastfeeding Determinants in Healthy Term Newborns. Nutrients 10: https://doi. org/10.3390/nu10010048

39. Lauria L, Spinelli A, Grandolfo M (2016) Prevalence of breastfeeding in Italy: a population based follow-up study. Annali dell'Istituto Superiore di Sanità. https://doi.org/10.4415/ANN_16 0318

40. Regione Lombardia Sanità Prevalenza, esclusività e durata dell'allattamento al seno in Regione Lombardia

41. World Health Organization (2003) Global strategy for infant and young child feeding. WHO, Geneva 
42. Davidson EL, Ollerton RL (2019) Partner behaviours improving breastfeeding outcomes: An integrative review. Women Birth J Aust Coll Midwives. https://doi.org/10.1016/j.wombi.2019.05.010

43. Rempel LA, Rempel JK (2011) The breastfeeding team: the role of involved fathers in the breastfeeding family. J Hum Lact 27:115121. https://doi.org/10.1177/0890334410390045
Publisher's note Springer Nature remains neutral with regard to jurisdictional claims in published maps and institutional affiliations.

\section{Affiliations}

Beatrice Letizia Crippa ${ }^{1,2} \cdot$ Alessandra Consales $^{1,2} \cdot$ Daniela Morniroli ${ }^{1,2} \cdot$ Flavia Lunetto $^{2} \cdot$ Maria Enrica Bettinelli $^{2}$. Patrizio Sannino ${ }^{3}$. Serena Rampini ${ }^{3} \cdot$ Lidia Zanotta $^{1}$ - Paola Marchisio ${ }^{4,5}$ - Laura Plevani ${ }^{1}$. Maria Lorella Gianni ${ }^{1,2}$. Fabio Mosca ${ }^{1,2} \cdot$ Lorenzo Colombo $^{1,2}$

1 Fondazione IRCCS Cà Granda Ospedale Maggiore Policlinico, NICU, Milan, Italy

2 Department of Clinical Sciences and Community Health, Università degli Studi di Milano, 20122 Milan, Italy
3 Direzione Professioni Sanitarie, Fondazione IRCCS Ca' Granda Ospedale Maggiore Policlinico, Milan, Italy

4 Fondazione IRCCS Ca' Granda Ospedale Maggiore Policlinico, 20122 Milan, Italy

5 Università degli Studi di Milano, 20122 Milan, Italy 